\title{
A EDUCAÇÃO A DISTÂNCIA E A AUTONOMIA DO ALUNO
}

Talita Tardivo Rainha

Universidade Estadual de Maringá - UEM, Programa de Pós-Graduação em Educação. E-mail: talita.rainha@hotmail.com

\section{RESUMO}

O presente artigo traz parte dos resultados de uma pesquisa de mestrado desenvolvida junto ao Programa de Pós-Graduação em Educação da Universidade Estadual de Maringá - UEM. A proposta é elencar algumas das principais características da concepção de autonomia vinculada à Educação a Distância (EaD). O objetivo é de avançar na compreensão sobre o conceito de autonomia em EaD e nas peculiaridades que a educação mediada por tecnologias apresenta. Para tanto se utilizou como fundamentação teórica principalmente os escritos de Knowles, Moore, Garrison e Peters. A metodologia utilizada foi uma abordagem de cunho qualitativo e de natureza descritiva e explicativa. No âmbito das teorias dessa área, esse conceito se diferencia fundamentalmente pelo desenvolvimento dos ambientes online. Os resultados obtidos na pesquisa apontam que a concepção de autonomia em EaD trata-se de um modo de relacionamento complexo, com conteúdos e ferramentas interativas, disponíveis sobretudo em Ambientes Virtuais de Aprendizagem (AVA).

Palavras-chave: Autonomia; Educação a Distância; Aprendizagem online.

\section{THE DISTANCE EDUCATION AND THE LEARNER AUTONOMY}

\begin{abstract}
This article presents part of the results of a master's research developed by the Program for Graduate Education of the State University of Maringá. The aim is to list some of the main features of autonomy linked to Distance Education (DE-EaD). . The goal is to advance in the understanding of the concept of autonomy in Distance Education and the peculiarities that education mediated by technology presents. For this was used as a theoretical basis mainly the writings of Knowles, Moore, Garrison and Peters. The methodology used was a qualitative, descriptive and explanatory study approach. Within the scope of theories of this area, this concept is fundamentally different by the development of online environments. The results show that the concept of autonomy in Distance Education is a way of complex relationship with content and interactive tools, especially in Virtual Learning Environments (VLEs-AVAs) available.
\end{abstract}

Keywords: Autonomy; Distance Education; Online learning. 


\section{INTRODUÇÃO}

O desenvolvimento da Educação a Distância (EaD) no Brasil é um fato que vem sendo observado com o crescimento da oferta de cursos superiores a distância, sobretudo a partir de 1996. A implementação de políticas públicas neste setor e as transformações ocorridas na legislação educacional abriram campo para a consolidação da modalidade no cenário nacional. Com a implementação desses cursos, ouve também o aumento na publicação de estudos e pesquisas que têm como temática central a modalidade a distância. Neste cenário, um assunto recorrente é o estilo de aprendizagem, mas particularmente a autonomia do educando que a esta modalidade é relacionada.

A vinculação entre os objetivos do processo educacional e os ideais de autonomia aparece como um elemento comum nos mais variados discursos pedagógicos que marcaram o século XX, assim como nas perspectivas educacionais para o século XXI. No pensamento moderno, muitos são as suas conotações que revelam uma profunda relação com as teorias e contexto sociopolítico em que são utilizadas. Portanto, o uso corrente do termo autonomia nos discursos relativos à educação devem ter o cuidado de trazer à tona as dimensões e características a que ele se vincula com vistas a um melhor entendimento e clareza da discussão.

Em uma pesquisa realizada por Faria, Faria e Pinto (2016) observou-se que a autonomia é ressaltada por diversos autores em publicações nacionais recentes como aspecto central da aprendizagem em EaD. Contudo, o emprego do conceito se confunde a outros como motivação e direcionamento, o que gera imprecisão e falta da correspondente fundamentação teórica.

No presente artigo, apresentamos parte do resultado da pesquisa realizada na dissertação sob autoria da autora supracitada. $O$ enfoque no texto que ora apresentamos tem como objetivo principal divulgar, esclarecer e avançar em alguns pontos essenciais para a compreensão do conceito de autonomia em Educação a Distância e das peculiaridades que a educação mediada por tecnologias apresenta.

\section{METODOLOGIA}

A metodologia empregada para investigar o conceito de autonomia na Educação a Distância foi uma abordagem de cunho qualitativo e de natureza descritiva e explicativa.

Para tanto, realizamos uma pesquisa bibliográfica, de modo a delinear a utilização do termo principalmente em autores como Peters, Moore, Knowles e Garrison. O recorte se justifica uma vez que cada um desses apresenta em suas teorias a discussão e delimitação conceitual do que seja esse ideal de autonomia em espaços educativos mediados pelas Tecnologias de Informação e Comunicação (TICs).

De acordo com Moreira (1999), a abordagem qualitativa exprime a complexidade e a dinâmica dos fenômenos sociais e humanos. Por meio da fundamentação de cunho conceitual, busca a compreensão de problemáticas relacionando-as ao contexto no qual o objeto de pesquisa se insere. No caso do objetivo aqui proposto, a compreensão do conceito de autonomia só pode ser compreendida em uma relação com a teoria e os objetivos educacionais que a fundamenta.

\section{RESULTADOS DA PESQUISA}

Os resultados da pesquisa apontam que a EaD sempre esteve vinculada à premissa de maior liberdade e engajamento do estudante. Isto se deve ao fato da não presencialidade incutir a ideia de maior exigência e responsabilidade para que o aluno evolua nos estudos.

A modalidade a distância, utilizada inicialmente por meio de cursos por correspondência, era marcada por uma forma instrucional de aprendizagem que exigia muito do aluno. Naquele contexto, a autoaprendizagem foi de fato uma característica predominante em cursos que não dispunham de ferramentas tecnológicas e de assistência contígua. 
Entretanto, cabe ressaltar que autoaprendizagem não é igual a autodidatismo. O autodidata é aquele que estuda e adquire instrução sem a orientação de um professor, criando suas próprias estratégias para a aquisição de conhecimento e buscando os instrumentos para sua formação. 0 termo corresponde à conduta de um sujeito em situação de aprendizagem, geralmente fora de um contexto institucional (SERAFINI, 2012).

Logo, o aluno da modalidade a distância, mesmo em cursos que apresentam fortes traços instrucionais, não pode ser considerado um autodidata, uma vez que tem material sistematizado a seu dispor, além de, muitas vezes, poder contar com auxílio e acompanhamento para sua aprendizagem.

Nos anos 1970, teve início uma nova fase para a EaD em nível internacional. A ferramenta de comunicação utilizada na modalidade passa da correspondência para a comunicação de massa por meios eletrônicos analógicos, como o rádio e a televisão. Como consequência, houve importantes mudanças pedagógicas que proporcionaram diferentes maneiras de se pensar novas abordagens, as quais, por sua vez, também modificaram a maneira de se pensar a EaD.

Dentre as principais características desse momento estão:

"[...] o considerável progresso na criação e no acesso à educação superior para grupos maiores de adultos, experimentação pedagógica, a aplicação cada vez maior de tecnologias educacionais, a introdução e a manutenção de aprendizado aberto e permanente e o inicio da educação superior em massa" (PETERS, 2009, p. 32).

Esses avanços para a modalidade trouxeram reconhecimento e intenso financiamento pelos governos no exterior, o que criou e fortaleceu as universidades a distância autônomas que atendem a milhões de estudantes em todo o mundo. $O$ impacto da crescente utilização da informatização e comunicação digital repercutiu em uma revolução pedagógica e em novos paradigmas sobre a aprendizagem. O desenvolvimento da concepção de autonomia em EaD surge nesse contexto, no qual se tem como perspectiva a aprendizagem online desenvolvida em Ambientes Virtuais de Aprendizagem (AVA) abertos, centrados no alunos, interativos e flexíveis quanto ao currículo.

Otto Peters, na obra A Educação a Distância em Transição (2009), aponta que a educação a distância é uma modalidade de ensino, educação e aprendizagem que não é de forma alguma bem definida ou fixa. Nela, podemos encontrar uma ampla gama de possibilidades para a organização dos cursos. Isso se desdobra em uma considerável variedade de maneiras de como o aluno aprende a distância. Assim, quando pensamos em uma formação autônoma do aluno, o modelo deve esmerar-se para tal.

Os AVA prometem muito nesse sentido. A aprendizagem em si não se torna virtual. Como ressalta Peters (2009), ela é sempre bem real. Entretanto, a maneira como a aprendizagem é iniciada, seus estímulos nos espaços virtuais e a interação com os conteúdos diferem em muitos aspectos dos espaços reais de aprendizagem.

Quando tratamos de autonomia relacionada a um modelo de curso, tratamos de independência para a aprendizagem. Tori (2015) ressalta que dar autonomia ao aluno significa desafiá-lo, instigá-lo, fazer com que encontre perguntas em vez de lhe dar respostas que ainda não pediu. Esta forma de relação consolida um maior envolvimento com consequente melhoria na aprendizagem.

\section{DISCUSSÃO}

No âmbito das principais teorias da área, a conotação de autonomia pode diferir de modo substancial conforme a perspectiva de aprendizagem e o delineamento da finalidade educativa ali proposta. Essas diferenciações repercutem na maneira como o Ambiente Virtual de Aprendizagem 
é organizado, nas ferramentas que estarão disponíveis para o aluno e, em grande parte, determinarão seu modo de interação e movimentação nesse espaço.

Peters (2009) salienta que a autonomia do educando não se refere apenas à tomada de decisões por iniciativa própria, mas a um conjunto de fatores processuais da aprendizagem. $\mathrm{Na}$ leitura de Rack (2011), Peters considera que a prática da autonomia não significa meramente uma particularidade técnico-organizacional da configuração educativa.

Para além do conhecimento do conteúdo, a competência de utilizar métodos para adquirilos e a cooperação para a construção de conhecimentos coletivos são enfatizadas. $O$ estudante, responsável pela própria aprendizagem, domina o processo pelo qual ela ocorre. "Como não há qualquer interferência de uma pessoa ou de uma instituição externa, este tipo de aprendizagem poderia ser chamado de autônomo" (PETERS, 2009, p. 102).

Um pioneiro no estudo de aprendizagem de adultos e que destaca o aspecto autodiretivo de aquisição de conhecimento é Malcom Knowles (1975). Em seus estudos e pesquisas, o autor trata da aprendizagem de adultos como um campo específico da ciência denominado andragogia. Embora esse conceito tenha se desenvolvido na década de 1830 , foi em sua teoria que ele se popularizou, acentuando as diferenças entre a aprendizagem de adultos e de crianças conforme a pedagogia tradicional (SMITH, 2002).

Na mesma ocasião em que Knowles desenvolvia sua teoria sobre andragogia, Michael Moore, atraído pelas ideias de independência do aluno desenvolvidas por Wedemeyer, escrevia sobre a possibilidade de a distância ser, contrariamente ao que muitos pensam, um fator positivo para os alunos. Na visão deste autor, os alunos adultos, individualmente ou em grupos, têm maior controle do seu aprendizado e maior independência..

Para além do conhecimento do conteúdo, a competência de utilizar métodos para adquirilos e a cooperação para a construção de conhecimentos coletivos são enfatizadas. O estudante, responsável pela própria aprendizagem, domina o processo pelo qual ela ocorre. "Como não há qualquer interferência de uma pessoa ou de uma instituição externa, este tipo de aprendizagem poderia ser chamado de autônomo" (PETERS, 2009, p. 102).

Um pioneiro no estudo de aprendizagem de adultos e que destaca o aspecto autodiretivo de aquisição de conhecimento é Malcom Knowles (1975). Em seus estudos e pesquisas, o autor trata da aprendizagem de adultos como um campo específico da ciência denominado andragogia. Embora esse conceito tenha se desenvolvido na década de 1830 , foi em sua teoria que ele se popularizou, acentuando as diferenças entre a aprendizagem de adultos e de crianças conforme a pedagogia tradicional (SMITH, 2002).

Na mesma ocasião em que Knowles desenvolvia sua teoria sobre andragogia, Michael Moore, atraído pelas ideias de independência do aluno desenvolvidas por Wedemeyer, escrevia sobre a possibilidade de a distância ser, contrariamente ao que muitos pensam, um fator positivo para os alunos. Na visão deste autor, os alunos adultos, individualmente ou em grupos, têm maior controle do seu aprendizado e maior independência em relação ao controle exercido pelas instituições educacionais (MOORE; KEARSLEY, 2007).

Outro enfoque sobre a autonomia relacionado ao diálogo e à estrutura do modelo é apresentada por Randy Garrison (2014). Sua discussão enfoca o princípio da proficiência, que se reporta à capacidade do aluno construir significado e ter disposição para iniciar e persistir em uma iniciativa de aprendizagem.

O aluno deve assumir a responsabilidade por criar significado a partir do conteúdo assimilado ou incluir ideias e conceitos novos em sua estrutura de conhecimento já existente. A partir daí, o conhecimento deve ser compartilhado como forma de comunicação recíproca que visa confirmar a compreensão e gerar conhecimento válido. Esse movimento intelectivo resulta no que o autor denomina aprendizado em colaboração e na construção social do conhecimento (MOORE; KEARSLEY, 2007). 
Essa perspectiva construtivista e colaborativa da aprendizagem se reforçou com os avanços tecnológicos, permitindo que a EaD pudesse se desenvolver rumo não apenas à veiculação de conteúdos considerados como formas de transmissão, mas, sobretudo, consolidando formas significativas de interação.

Observa-se nas teorias mencionadas uma preocupação em se compreender as variáveis do processo educacional mediado pelas tecnologias. O mérito de cada uma reside na tentativa de construção de uma teoria da educação a distância que possa organizar fatos e conceitos compartilhados, para que tornem possível a discussão, a análise e a crítica na área, evitando questões vagas, ou já respondidas, além do uso de vocabulários indefinidos, que torna as discussões confusas.

Por essa razão, um elemento a ser revisto é a identificação dos pressupostos teóricos e conceituais que nos referimos ao pensar na autonomia do aluno. No cenário nacional em que a educação na modalidade a distância cresce a cada dia, esse é um campo de estudo a ser desbravado para que se consolide contribuições para a prática educativa da EaD no Brasil.

\section{CONSIDERAÇÕES FINAIS}

A concepção de autonomia em EaD desenvolve-se enquanto perspectiva de aprendizagem situada em Ambientes Virtuais de Aprendizagem abertos, centrados nos alunos, que pressupõem um modo de relação interativa com os conteúdos e uma estrutura flexível quanto ao currículo.

Para finalizar, ressaltamos que as concepções de autonomia em EaD possuem, assim como outros termos na área, o seu significado estendido e transformado. A informatização no campo da aprendizagem traz consequências que diferem em muitos aspectos do conhecimento tradicional. Defrontamo-nos com formas diferentes de transmissão e relação com informações e conhecimento que implicam no que Peters denomina um "lidar com" (2009, p. 353); esses conteúdos que trazem novas formas de comportamentos de aprendizagem que recebem um significado anteriormente desconhecido.

Mais do que isso, para que ocorra um domínio do gerenciamento do conhecimento no campo da aprendizagem online, um objetivo pedagógico primordial é o esclarecimento sobre o modo como se dá esse conhecimento para que as pessoas tenham domínio dos processos e mecanismos intrínsecos a essa diferente maneira de se aprender.

\section{REFERÊNCIAS}

FARIA, M.; FARIA, B.; PINTO, A. Tecnologias de apoio à aprendizagem como fatores de motivação de alunos em cursos a distância. In: Simpósio Internacional de Educação a Distância, 1, 2016, São

Carlos. Disponível em: <http://www.siedenped2016.ead.ufscar.br/ojs/index.php/2016/article/view/1508> Acesso em: 20 jul. 2016.

GARRISON, Randy; CLEVELAND, Martha. Facilitating Cognitive Presence in Online Learning: Interaction Is Not Enough, American Journal of Distance Education, v. 19, n. 3, p. 133-148, 2005. Disponível em: <http://www.tandfonline.com/doi/abs/10.1207/s15389286ajde1903 2\#.U07Ev15> Acesso em: 16 abr. 2014.

KNOWLES, M. S. Self-Directed Learning: a guide for learners and teachers, Englewood Cliffs: Prentice Hall/Cambridge, 1975.

MOORE, Michael G.; KEARSLEY, Greg. Educação a Distância: uma visão integrada. São Paulo: Thompson Learning, 2007. 
MOREIRA, M. A. Sobre o ensino do método científico. Caderno Catarinense de Ensino de Física, Florianópolis, v. 10, n. 1, 1999.

PETERS, Otto. A Educação a distância em transição: tendências e desafios. São Leopoldo, RS: Ed. Unisinos, 2009.

RACK, Josias Ricardo. Introdução à Educação a distância. Florianópolis: LLV/CCE/UFSC, 2011.

SERAFINI, Alessandra Menezes dos Santos. A idealização e a realidade: a autonomia do aluno em Educação a Distância. 2012. 152f. Dissertação (Mestrado em Educação)-Universidade Fedarla de Juiz de Fora, Juiz de Fora, MG, 2012.

SMITH, M. K. Malcolm Knowles, informal adult education, self-direction and andragogy. The encyclopedia of informal education, 2002. Disponível em: <www.infed.org/thinkers/etknowl.htm>. Acesso em: 09 abr 2014.

TORI, Romero. Tecnologia e metodologia para uma educação sem distância. Revista Em Rede. Porto Alegre: Unirede. $2015 . \quad$ Disponível em: $<$ http://www.aunirede.org.br/revista/index.php/emrede/article/view/64/82>. Acesso em 08 ago. 2016. 